\title{
ANATOMIA DO XILEMA SECUNDARIO DE Indigofera suffruticosa Miller
}

Josē Newton Cardoso Marchiori

Departamento de Ciências Florestais. Centro de Ciências Rurais. UFSM. Santa Maria, RS.

RESUMO

E descrita a madeira de Indigofera suffruticosa Mill. e apresentados dados quantitativos dos tipos celulares constituintes. A estrutura anatômica é comparada com referēncias da literatura pa ra a espēcie e gēnero botânico em questão.

\section{SUMMARY}

MARCHIORI, J.N.C., 1986. Secondary Xylem Anatomy of Indigofera suffru ticosa Mi11. Ciência e Natura, 8:105-114.

The wood anatomy of Indigofera suffruticosa Mill. is des cribed, beeing presented quantitative data of its cellular types. The anatomical structure is compared with literature references to the species and botanical genus concerned.

INTRODUÇÃO

0 gēnero Indigofera L. compreende mais de 250 espéciestro picais e subtropicais em todo o mundo. São plantas heliōilas que habitam estepes e savanas graminosas, sendo especialmente abundan tes na Äfrica (BURKART, 1). No Estado do Rio Grande do Sul são cita das por RAMBO (8) as ocorrēncias de Indigofera asperifolia Bong., I. campestris Bong. e I isabulicola Bentham, alēm de Indigofera suffruticosa Mil1.

A espécie em estudo é conhecida pelos nomes populares de anil e.anileiro (SCHuLTZ, 10). E origināria das Antillhas e Amērica Central, sendo sub-espontânea em todo o Brasil (PIO CORREA, 7). No Rio Grande do Sul, é encontrada em todo o Estado, sempre em solos alterados (RAMBO, 8). LOMBARDO (5) cita a espēcie para as margensdo rio Uruguai, no vizinho pais homônimo.

0 anileiro ocorre de preferência em capoeiras e prefere os solos argilosos férteis, não excessivamente úmidos (LEITÃo FILHO et alii, 4). E um arbusto perene, de 1,5 a $2,5 \mathrm{~m}$ de altura, com cau les ramificados de cor castanho-clara e folhas compostas de 7 a 15 folĩolos, que são opostos com excessão do terminal. os frutos são arqueados, de forma muito característica, e encontram-se dispostos abundantemente em racemos axilares retos.

Indigofera suffruticosa produz um anil de melhor qualida de do que I. tinctoria L. e I. sumatrana Gaertn., que são originā rias do oriente. Antes da descoberta e fabricação das anilinas 
sintēticas, estas três espécies foram objeto de intenso cultivo na Asia e Amērica Tropical (PIO CORREA, 7).

A anatomia da madeira foi pouco pesquisada no gênero Indi gofera L., provavelmente porque se tratam de plantas com caules de diāmetro imcompatīvel à utilização do lenho. No presente trabalho é realizada a descrição anatōmica detalhada da madeira, da espécie mais frequente no Rio Grande do Sul.

\section{REVISÃO DA LITERATURA}

A anatomia das espēcies americanas de Indigofera dispõe de referências bibliogräficas reduzidas, carecendo as mesmas de estu dos detalhados. O gênero não foi abordado nas obras básicas de RE CORD \& HESS (9) e TORTORELLI (11). Apenas Indigofera gerardianaWall. e I. suffruticosa Mill. foram analisadas mais atentamente, em traba Tho sobre a anatomia do lenho secundário das leguminosas papiliono $i$ deas da Argentina, datado de 1950.

METCALFE \& CHALK (6) referem para Indigofera e outros 11 gêneros de Papilionaceae, a ocorrência de poros moderadamente peque nos, entre 50 e $100 \mu \mathrm{m}$. Indigofera é incluĩda, pelos mesmos autores, na relação dos 27 gêneros da referida famîlia, que apresentam poro sidade em anel ou em semi-anel, pelo menos em algumas de suas espé cies.

cozzo (3) fornece para as duas espécies argentinas porele estudadas, valores de $18-55-85 \mu \mathrm{m}$, como diâmetro tangencial mí nimo, mēdio e māximo de poros, respectivamente. A porosidade é des crita como difusa, sem ordenação especial, na qual os poros são so 1 itārios ou em curtos mūitiplos, de forma oval a sub-oval e com pá rede secundāria delgada. De acordo com cozzo (3), a frequência de poros varia, nas duas espēcies, entre 27 e 63 , com valor médio igual a 33 poros por $\mathrm{mm}^{2}$.

cozzo (3) fala em elementos vasculares de trajeto retili neo e com placas de perfuração simples, ocorrendo em tabiques hor zontais. En Indigofera suffruticosa, o mesmo autor refere vasos de curso atē muito sinuoso e com apēndices ausentes, ou curtos até me dianos. Para as duas espécies argentinas são fornecidos os valores de 100 - 160 - $240 \mu \mathrm{m}$, como comprimento mînimo, médio e máximo de elementos vasculares, respectivamente.

METCALFE \& CHALK (6) citam para Papilionaceae a ocorrēn cia de pontuações intervasculares ornamentadas, alternas e tipica mente pequenas. Em Indigofera suffruticosa as pontuações são de gran de tamanho, semi-escalariformes, com aréola ovalada e abertura oblon go-oval ( Cozzo, 3).

Com relação ao parênquima axial, METCALFE \& CHALK (6) in cluem Inäigofera na relação dos 11 gēneros de Papilionāceas que 
apresentam parênquima axial moderado a muito abundante, intermediá rio entre os tipos aliforme e confluente, bem como na lista de 19 gêneros da mesma famỉlia em que ocorrem espécies com parênquimaxial predominantemente vasicêntrico. $\operatorname{cozzo}$ (3) refere para I. suffrutico sa parênquima difuso, escassamente paratraqueal, atē nitidamente pa ratraqueal e de difícil reconhecimento. Para $I$. gerardiana o parên quima è descrito como abundante, difuso, terminal, vasicêntrico e até em faixas curtas e estreitas.

Para Indigofera e outros 20 gêneros de Papilionáceas, MEI CALFE \& CHALK (6) referem a ocorrência de raios uni-seriados, com apenas ocasionais bi-seriados. 0 mesmo autor descreve para o gênero em estudo, juntamente com Hebestigma, Kunstleria e Lupinus, a pre sença de raios moderadamente heterogêneos, dos tipos II e ocasional mente III de Kribs, com 4 ou mais fileiras marginais de cēlulas ere tas. METCALFE \& CHALK (6) referem-se, ainda, a cēlulas procumbentes. de diâmetro tangencial muito pequeno, menores de $10 \mu \mathrm{m}$, para Indigo fera e outros 17 gêneros da famîlia.

Em Indigofera suffruticosa os raios tem forma linear e são do tipo Heterogēneo II $A(C O Z Z O, 3)$. Para uma das amostras analiza das, o mesmo autor descreve a ocorrência de raios predominantemente uni-seriados, com poucos bi e tri-seriados que, neste caso, exibem numerosas cēlulas envolventes.

Em chave de identificação anatômica, cozzo (3) distingue Indigofera suffruticosa de $I$. gerardiana, pela ausência na prime ra de estrutura estratificada e ocorrência de raios altos, de até $1330 \mu \mathrm{m}$, unitseriados e com escassos 2-3-seriados.

As fibras de Papilionaceae tem pontuações escassas, peque nas, simples e mais numerosas na face radial do que tangencial da parede celular (METCALFE \& CHALK, 6). Os mesmos autores observam, ainda, que fibras septadas ocorrem muito ocasionalmente na familia, citando a característica para apenas ougeneia, Robinia, Sophora e Tipuana.

Para as duas espécies argentinas investigadas, cozzo refere fibras de tipo libriforme, com comprimento mëdio de $530 \mu \mathrm{m}$, bem como abundante fibrotraqueōides e fibras gelatinosas. 0 autor cita, ainda, a ocorrência de traqueóides vasicêntricos e vasculares, mas observa que estes elementos encontram-se em pequenas quantida des na madeira.

\section{MATERIAL E METODOS}

0 material estudado é procedente do Estado do Rio Grande do sul e consiste de amostras de madeira e respectivas exsicatas bo tânicas, guardadas na Xiloteca e Herbārio do Departamento de Ciên cias Florestais (HDCF) da Universidade Federal de Santa Maria, com 
os seguintes registros:

- HDCF 277. Marchiori, J.N.C.; Alvarez Filho, A. \& Longhi, S.J., s/n. Nova Boēmia, Agudo, RS. 08-4-1981.

- HDCF 2107. Marchiori, J.N.C. nọ 155. Cerrito, Santa Maria - RS. $27-12-1985$.

Das amostras de madeira foram preparados bloquinhos e ob tidos finos cortes anatômicos nos planos transversal, longitudinal radial e longitudinal tangencial. Os cortes, com espessura nominal de $18 \mu \mathrm{m}$, foram obtidos em micrótomo de deslizamento, coloridos com safranina e azul de astra, e montados em lâminas permanentes, tendo sido usado Entellan como meio de montagem.

Foram preparados tambēm lâminas de células dissociadas de madeira, mediante a maceração de finos palitos em solução de ácido nîtrico $10 \%$ e ácido crômico $10 \%$, em partes iguais, coloração com sa franina e o mesmo meio de montagem anteriormente citado.

As medições anatômicas e a descrição da madeira foram rea Hizadas com base na Norma COPANT (2). Os dados quantitativos são apresentados na Tabela I. As fotomicrografias da Figura 1 foram to madas em aparelho da casa Carl Zeiss.

DESCRIÇAO DA MADEIRA

CARACTERES GERAIS E ORGANOLEPTICOS

Madeira de cerne e alburno indistintos, brilhante, de cor claro-amarelada, de grã direita ou linheira, não aromática, macia e de textura fina.

\section{DESCRIÇO MACROSCOPICA}

Poros: Invisīveis a olho nū em plano transversal, pequenos, pouco numerosos, em distribuição difusa e uniforme. Poros sem conteüdo, solitārios em sua maioria, geminados e, mais raramente em múltiplos radiais curtos. Linhas vasculares retilíneas, mostrando conteúdo com aspecto de goma e cor laranja-avermelhado em alguns vasos.

Parênquima axial: Invisível a olho nū em plano transversal, visĩvel com dificuldade sob lente ou lupa de $10 \mathrm{x}$, escasso e em disposição predominantemente paratraqueal vasicêntrica.

Raios: Praticamente invisīveis a olho nū em plano transversal, visí veis sem dificuldade sob lente ou lupa de $10 \mathrm{x}$, finos, numerosos. Em plano longitudinal tangencial, visĩveis sem dificuldade sob lente ou lupa, baixos, não estratificados. Espelhado dos raios pouco contras tado dos tecidos axiais, em plano longitudinal radial.

Anéis de Crescimento: Distintos, individualizados por parēnquima mar ginal.

outros caracteres: Canais secretores axiais, mäculas medulares, lïber 
incluso e listrado de estratificação, ausentes.

DESCRIÇ AOO MICROSCOPICA

Vasos: Muito numerosos (25 - 35 - 65 por $\mathrm{mm}^{2}$ ) e ocupando $14,5 \%$ da secção transversal da madeira. Poros pequenos $(32,5-60,9-82,5$ $\mu \mathrm{m})$, de secção oval, em distribuição difusa, uniforme, e dispostos predominantemente como solitārios ou em mūitiplos de 2 a 4 , em agru pamentos radiais; agrupamentos em cacho, raros, e formado de poucos elementos. Poros de parede celular delgada $(1,3-2,5-5 \mu m)$ e ap $\underline{a}$ rentemente sem conteūdos. Elementos vasculares muito curtos (105 $162,5$ - $225 \mu \mathrm{m})$, com placa de perfuração simples e geralmente trans versal ao vaso, desprovidos de espessamentos espiralados e outras estriações na parede celular, e usualmente desprovidos de apēndi ces. Quando presentes, os apēndices são curtos $(5,0-21,6-75 \mu m)$, ocorrendo geralmente em apenas uma das extremidades.

Pontuado intervascular alterno. Pontuações de diāmetro tangencial pequeno a mēdio $(5,3-6,8-9,8 \mu \mathrm{m})$, de forma oval a le vemente poligonal devido à aproximação das mesmas e ornamentadas. Abertura interna em forma de fenda, horizontal, inclusa ou coales cente a 2 pontuações; abertura externa, de forma oblongo-oval.

Pontuações rádio-vasculares, pequenas em sua maioria (4 5,2 - $8 \mu \mathrm{m})$, arredondadas, e em arranjo alterno. Pontuações, parēn quimo-vasculares pequenas $(4,5-5,7-7 \mathrm{~m})$, semelhantes às ante riores. Traqueóides vasicēntricos, traqueōides vasculares e elemen tos vasculares imperfeitos, não observados.

Parênquima radiaz: Pouco abundante, compondo em mēdia $12,1 \%$ da sec ção transversal da madeira. Parēnquima axial em disposição paratra queal vasicêntrica, aliforme-confluente e formando curtas faixastan genciais; paratraqueal marginal e com cēlulas apotraqueais difusas tambēm presente no tecido fibroso.

Cēlulas parenquimāticas geralmente retangulares, com 60 80 - $100 \mu \mathrm{m}$ de altura por 10 - 17,5 - $25 \mu \mathrm{m}$ de largura; em séries de duas, mas até 4 cēlulas, e altura de 125 - 163,7 - $195 \mu \mathrm{m}$. Célu las fusiformes mais raras, com 90 - 157 - 212,5 $\mu \mathrm{m}$ de altura e 6,313,9 - $25 \mu \mathrm{m}$ de largura. Sēries cristalïferas com cristais rombó des em até 8 cámaras, pouco frequentes e ocorrendo especialmente na margem do parênquima paratraqueal.

Raios: Muito numerosos (9-11,8 - $15 \mathrm{raios} / \mathrm{mm}$ ) e com fração deārea igual a $12,4 \%$, em mēdia. Tendo radial heterogêneo, de tipo II.

Raios-uni-seriados extremamente numerosos ( 44 - 48 53\% dos raios), compostos de cēlulas quadradas e eretas, extremamente finos $(6,2-11-22,5 \mu \mathrm{m})$, extremamemte baixos $(25-110,9-325,5 \mu \mathrm{m}) \mathrm{e}$ com $1-5$ - 15 cēlulas de altura. 
TABELA I. DADOS QUANTITATIVOS DA ESTRUTURA ANATÔMICA DA MADEIRA.

\begin{tabular}{|c|c|c|c|c|}
\hline CARACTERISTICA ANATŌMICA & $\begin{array}{l}\text { VALOR } \\
\text { MINIMO }\end{array}$ & MEDIA & $\begin{array}{l}\text { VALOR } \\
\text { MAXIMO }\end{array}$ & $\begin{array}{l}\text { DESVIO } \\
\text { PADRAO }\end{array}$ \\
\hline 1. Frequência de poros (poros $/ \mathrm{mm}^{2}$ ) & 25,0 & 35,0 & 65,0 & 7,12 \\
\hline 2. Fração de poros (\%) & 12,0 & 14,5 & 21,0 & 2,87 \\
\hline 3. $\emptyset$ tangencial de poros $(\mu \mathrm{m})$ & 32,5 & 60,9 & 82,5 & 11,05 \\
\hline 4. Espessura parede de poros $(\mu \mathrm{m})$ & 1,3 & 2,5 & 5,0 & 0,76 \\
\hline 5. Comprimento elementos vasculares $(\mu \mathrm{m})$ & 105,0 & 162,5 & 255,0 & 27,58 \\
\hline 6. Comprimento de apêndices $(\mu \mathrm{m})$ & 5,0 & 21,6 & 75,0 & 17,10 \\
\hline 7. $\emptyset$ pontuações intervasculares $(\mu \mathrm{m})$ & 5,3 & 6,8 & 9,8 & 1,06 \\
\hline 8. $\emptyset$ pontuações rādio-vasculares $(\mu \mathrm{m})$ & 4,0 & 5,2 & 8,0 & 0,94 \\
\hline 9. Ø pontuações parênquimo-vasculares $(\mu \mathrm{m})$ & 4,5 & 5,7 & 7,0 & 0,68 \\
\hline 10. Fração parēnquima axial (\%) & 6,0 & 12,1 & 18,0 & 3,78 \\
\hline 11. H. células parēnquima fusiforme $(\mu \mathrm{m})$ & 90,0 & 157,4 & 212,5 & 24,24 \\
\hline 12. L. cēlulas parênquima fusiforme ( $\mu \mathrm{m})$ & 6,3 & 13,9 & 25,0 & 4,46 \\
\hline 13. H. sēries parênquima axial $(\mu \mathrm{m})$ & 125,0 & 163,7 & 195,0 & 16,47 \\
\hline 14. H. sēries parēnquima axial (cēlulas) & 2,0 & 2,1 & 4,0 & 0,43 \\
\hline 15. H. células parēnquima seriado $(\mu \mathrm{m})$ & 60,0 & 80,0 & 100,0 & 9,04 \\
\hline 16. L. cềlulas parēnquima seriado $(\mu \mathrm{m})$ & 10,0 & 17,2 & 25,0 & 4,07 \\
\hline 17. Fração recido radial (\%) & 7,0 & 12,4 & 19,0 & 3,94 \\
\hline 18. Frequência de raios (raios $/ \mathrm{mm}$ ) & 9,0 & 11,8 & 15,0 & 1,49 \\
\hline 19. Fração raios uni-seriados (\%) & 44,0 & 48,0 & 53,0 & 2,94 \\
\hline 20. H. raios uni-seriados $(\mu \mathrm{m})$ & 25,0 & 110,9 & 353,5 & 53,85 \\
\hline 21. H. raios uni-seriados (cēlulas) & 1,0 & 4,8 & 15,0 & 2,29 \\
\hline 22. L. raios uni-seriados $(\mu \mathrm{m})$ & 6,2 & 11,0 & 22,5 & 3,18 \\
\hline 23. Fração raios bi-seriados (\%) & 27,0 & 36,7 & 45,0 & 5,65 \\
\hline 24. Fração raios tri-seriados (\%) & 8,0 & 13,6 & 22,0 & 4,69 \\
\hline 25. Fração raios tetra-seriados (\%) & 1,0 & 1,7 & 3,0 & 1,15 \\
\hline 26. H. raios multi-seriados $(\mu \mathrm{m})$ & 107,5 & 288,4 & 710,0 & 163,20 \\
\hline 27. H. raios multi-seriados (células) & 6,0 & 15,2 & 40,0 & 8,72 \\
\hline 28. L. raios multi-seriados $(\mu \mathrm{m})$ & 11,3 & 17,7 & 27,5 & 3,70 \\
\hline 29. L. raios multi-seriados (cēlulas) & 2,0 & 2,4 & 4,0 & 0,56 \\
\hline 30. Fração de fibras (\%) & 53,0 & 61,0 & 65,0 & 3,81 \\
\hline 31. Comprimento de fibras $(\mu \mathrm{m})$ & 550,0 & 674,4 & 770,0 & 57,00 \\
\hline 32. $\emptyset$ total de fibras $(\mu \mathrm{m})$ & 7,5 & 11,9 & 16,3 & 2,00 \\
\hline 33. $\emptyset$ do lümem de fibras $(\mu \mathrm{m})$ & 3,7 & 7,7 & 12,5 & 2,03 \\
\hline 34. Espessura parede de fibras $(\mu m)$ & 1,2 & 2,1 & 3,1 & 0,36 \\
\hline
\end{tabular}

Raios multi-seriados predominantemente com duas cēlulas de largura $(36,7 \%)$, menos frequentemente tri-seriados $(13,6 \%)$, raros tetra-seriados $(1,7 \%)$; muito finos $(11,3-17,7-27,5 \mu \mathrm{m})$, de ex tremamente baixos a muito baixos (107,5 - 288,4 - 710 $\mu \mathrm{m})$ e com 6 15 - 40 células de altura. Os raios multi-seriados são compostos de 

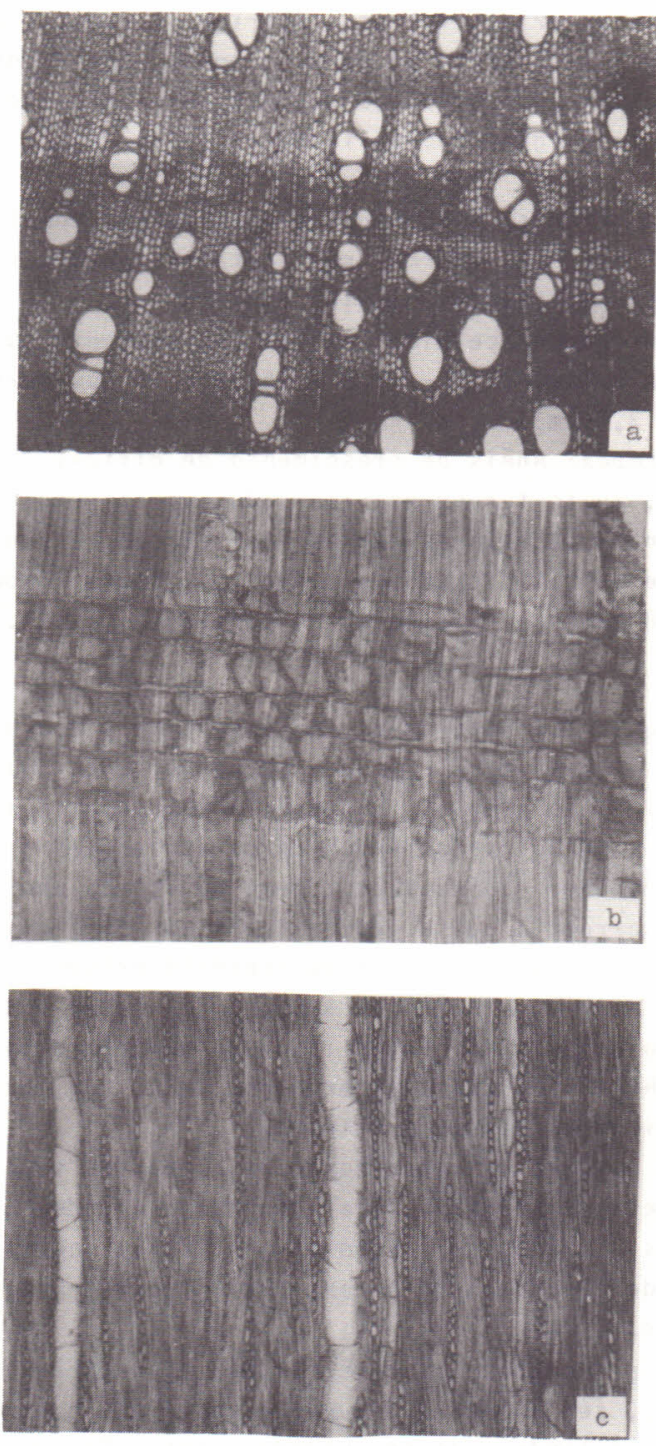

Figura 1. Fotomicrografias da madeira.

a) Corte transversal, $55 x$.

b) Corte longitudinal radial, $139 x$.

c) Corte longitudinal tangencial, $55 x$.

cēlulas curtamente procumbentes e margens uni-seriadas curtas, oca sionalmente muito longas, de cēlulas quadradas e eretas. Em plano longitudinal tangencial observam-se, com frequência, cêlulas envolven tes dispostas no corpo multi-seriado e central dos raios. 
Células cristalîferas, latericuliformes, esclerosadas e oleiferas, ausentes. Raios em geral normais, com frequentes fusiona dos identificados pela presença de duas ou mais partes multi-seria das ligadas por margens uni-seriadas entre si. Raios agregados, au sentes.

Eibras: Tecido fibroso predominante na madeira, constituindo $61 \%$ de seu volume. Fibras libriformes não septadas, geralmente gelatinosas e com numerosas pontuações simples e diminutas, mais abundantes na face radial da parede celular. Fibras extremamente curtas (500-674 - $770 \mu \mathrm{m})$, estreitas $(7,5-11,9-16,3 \mu \mathrm{m})$ e com paredes delgadas $(1,2-2,1-3,1 \mu \mathrm{m})$.

outros caracteres: Anēis de crescimento de difícil reconhecimento microscópico, muito tenuemente indicados por parênquima marginal.

Canais secretores, tubos lacticiferos e taniniferos, 1 i ber incluso e estratificação, ausentes. Cristais rombóides, em sé ries de até 8 câmaras, presentes no parēnquima axial.

DISCUSSAOO

Alguns dos caracteres anatômicos mais conspícuos em Indi gofera suffruticosa, tais como pontuações ornamentadas e pequenas, placa de perfuração simples, pontuado intervascular alterno, elemen tos vasculares muito curtos e fibras de pontuações simples, de pe queno comprimento e não septadas, tem, de acordo com METCALFE \& CHALK (6), ocorrência quase géneralizada em Papilionaceae.

A descrição anatómica do presente estudo concorda com as referēncias de COZzo (3) e METCALFE \& CHALK (6) sobre o diâmetro tangen cial mēdio no gênero. Por outro lado, ao contrārio do citado por METCALFE \& CHALK (6), mas de acordo com Cozzo (3), encontrou-se po ros em distribuição difusa e uniforme.

os valores de comprimento de elementos vasculares, encon trados no presente trabalho, praticamente coincidem com os dados de cozzo (3). As citações do anatomista argentino sobre a forma, espes sura de parede e arranjo de poros, tambēm correspondem ao descrito presentemente.

As pontuações intervasculares, ao contrārio do referido por cozzo (3), tem diâmetro pequeno a mëdio e encontram-se em arran jo alterno, não tendo sido encontradas pontuações de grande tamanho e semi-escalariforme.

A descrição do parênquima axial de Inaigofera suffrutico sa não colide com as referências de METCALFE \& CHALK (6) para o gê nero e corresponde à caracterização realizada por cozzo (3) para a mesma espēcie.

Os raios foram descritos com Heterogêneos II e concordam com o exposto por cozzo (3), inclusive sobre a ocorrência de cēlulas 
envolventes, presença excassa de raios 2-3-seriados e ausência de estratificação. No presente trabalho quantificou-se a frequência dos tipos de raios quanto à largura em número de cēlulas, tendo-se cons tatado uma larga predominância dos uni-seriados, variando de 44 a $53 \%$.

Não foram encontrados fibrotraqueóides, traqueōides vasi cēntricos e traqueóides vasculares, ao contrārio do referido por cozzo (3). As fibras mostraram ter comprimento ligeiramente maior do que o valor médio fornecido por cozzo (3) para as duas espécies argentinas investigadas.

CONCLUSÕES

A descrição e anālise da estrutura anatômica da madeira de Indigofera suffruticosa Mil1. mostram que:

1. A espēcie apresenta muitos caracteres anatômicos evoluídos, os quais tambēm ocorrem de maneira generalizada em madeiras de Legu minosae Papilionoideae.

2. Não ocorrem estratificação e espessamentos espiralados, caracte risticas moderadamente comuns na famīia.

3. A descrição anatómica da madeira coincide, de modo geral, com as referēncias bibliogräficas para o gênero e espécie em questão.

4. Não foram observados fibrotraqueóides, traqueóides vasicêntricos e traqueóides vasçulares, ao contrārio do afirmado na literatura.

REFERENCIAS BIBLIOGRĀFICAS

1. BURKART, A. Las Leguminosas Argentinas Silvestres y Cultivadas. Buenos Aires, ACME Agency, 1952. 569 p.

2. COPANT. COMISSION PANAMERICANA DE NORMAS TECNICAS. Descricion de caracteristicas generales, macroscopicas y microscopicas de Zas maderas de Angiospermas Dicotiledóneas. COPANT, 30:1-019, 1974.

3. Cozzo, D. Anatomia del leño secundario de las Leguminosas Papi lionoideas Argentinas silvestres y cultivadas. Rev. del Inst. Nac. de Ciencias Naturales Bemardino Rivadavia - C. Botāni cas, 1(7):223-361, 1950 .

4. LEITÃO FILHO, H. de F.; ARANHA, C. \& BACCHI, O. Plantas invaso ras de culturas nọ Estado de são Pauzo. Vol. II. São Paulo, HUCITEC: Ministērio da Agricultura, Agiplan, Banco Interameri cano de Desenvolvimento, 1972. $597 \mathrm{p}$.

5. LOMBARDO, A. Elora arborea y arborescente del Uruguay. Montevi deo, Concejo Departamental, s/d. $151 \mathrm{p}$.

6. METCALFE, C.R. \& CHALK, L. Anatomy of the Dicotyzedons. oxford, Clarendon Press, 1972. 1500 p.

7. PIO CORREA, M. Dicionário das Plantas Utteis do Brasil e das Exóticas 
Cultivadas. Vol. I. Rio de Janeiro, Imprensa Nacional, 1926. $747 \mathrm{p}$.

8. RAMBO, B. Leguminosae Riograndenses. São Leopoldo, Instituto An chietano de Pesquisas, 1966. 166 p. (Pesquisas, Sērie Botāni ca; Bol. no 23).

9. RECORD, S.J. \& HESS, R.W. Timbers of The New World. New Haven, Yale University Press, 1949. $640 \mathrm{p}$.

10. SCHULTZ, A.R. os nomes cientificos e populares das plantas do Rio Grande do SuZ. Porto Alegre, PUC/EMMA, 1975. 164 p.

11. TORTORELLI, L.A. Maderas y bosques argentinos. Buenos Aires, ACME, 1956. $910 \mathrm{p}$.

Recebido em junho, 1986; aceito em junho, 1986. 